\title{
High Resolution Photoelectron Spectroscopy of Clusters of Group V Elements
}

\author{
Lai-sheng Wang, B. Niu, Y.T. Lee and D.A. Shirley \\ Department of Chemistry, University of California \\ and Materials and Chemical Sciences Division \\ Lawrence Berkeley Laboratory, 1 Cyclotron Road \\ Berkeley, CA 94720 (U.S.A.)
}

\section{DISCLAIMER}

This report was prepared as an account of work sponsored by an agency of the United States Government. Neither the United States Government nor any agency thereof, nor any of their employees, makes any warranty, express or implied, or assumes any legal liability or responsibility for the accuracy, completeness, or usefulness of any information, apparatus, product, or process disclosed, or represents that its use would not infringe privately owned rights. Reference herein to any specific commercial product, process, or service by trade name, trademark, manufacturer, or otherwise does not necessarily constitute or imply its endorsement, recommendation, or favoring by the United States Government or any agency thereof. The views and opinions of authors expressed herein do not necessarily state or reflect those of the United States Government or any agency thereor. 


\section{Abstract}

High resolution Hel $(580 \AA)$ photoelectron spectra of $\mathrm{As}_{2}, \mathrm{As}_{4}$ and $\mathrm{P}_{4}$ were obtained with a newly-built high temperature molecular beam source. Vibrational structure was resolved in the photoelectron spectra of the three cluster species. The Jahn-Teller effect is discussed for the ${ }^{2} \mathrm{E}$ and ${ }^{2} \mathrm{~T}_{2}$ states of $\mathrm{P}_{4}{ }^{+}$and $\mathrm{As}_{4}{ }^{+}$. As a result of the Jahn-Teller effect, the ${ }^{2} E$ state splits into two bands, and the ${ }^{2} \mathbf{T}_{2}$ state splits into three bands, in combination with the spin-orbit effect. It was observed that the $v_{2}$ normal vibrational mode was involved in the vibronic interacton of the ${ }^{2} E$ state, while both the $v_{2}$ and $v_{3}$ modes were active in the ${ }^{2} \mathrm{~T}_{2}$ state. 


\section{Introduction}

Clusters bridge the gap between isolated atoms and molecules on one hand and condensed matter on the other. Research on clusters has received great attention in recent years [1]. One ceitral question in cluster research is the change of electronic properties as a function of cluster size. Photoelectron spectroscopy should be a powerful technique in this study, because it probes directly the electron energy levels of matter. However, a difficulty in applying photoelectron spectroscopy to cluster systems is need for sizeselectivity. As a result, much of the effort in studying the electronic structure of clusters has been focused on the photodetachment of negatively-charged clusters $[2,3]$. We are only beginning to see photoemission studies on size-selected neutral clusters [4].

We are interested in the high resolution photoelectron spectroscopy of neutral clusters. A high tempezature molecular beam source has recently been built to study neutral clusters and other high temperature species [5]. The Group V elements were chosen for our initial study because they provide an easy solution for the size-selectivity. The vapor phases of these elements are mainly composed of tetramers for P, As, and Sb, and dimers and atomic species for $\mathrm{Bi}[6]$. Diatomics of $\mathrm{P}, \mathrm{As}$, and $\mathrm{Sb}$ can be produced by pyrolyzing the tetramers [7], or by evaporating appropriate compounds of these elements [8]. Low resolution HeI photoelectron spectra of $\mathrm{P}_{2}$ [7,9,10], $\mathrm{P}_{4}$ [10-12], $\mathrm{As}_{2}$ [13,14], As 4 [13,14] and $\mathrm{Sb}_{4}[15,16]$ have been reported before. In this paper, we present the high resolution HeI photoelectron spectra of $\mathrm{As}_{2}, \mathrm{As} s_{4}$, and $\mathrm{P}_{4}$. Vibrational structure was resolved for all three species, allowing us to do more detailed analyses on

the spectroscopy of the final states. Especially for the ${ }^{2} \mathrm{E}$ and ${ }^{2} \mathrm{~T}_{2}$ states of $\mathrm{P}_{4}{ }^{+}$and $\mathrm{As}_{4}{ }^{+}$, the vibrational analyses enable us to gain insight into the Jahn-Teller effect.

\section{Experimental}


The photoelectron spectrometer [17] and the high temperature molecular beam source [5] have been described in detail elsewhere. Only a brief description is given here. The spectrometer consists of the beam source, a rare gas discharge lamp, a quadrupole mass spectrometer and a hemispherical electron energy analyzer with a multichannel detector.

The high temperature molecular beam source used electron bombardment heating and graphite crucibles with carrier gas entrainment. The experimental conditions are shown in Table I. All the samples were commercially available from CERAC.

Either $\mathrm{Ar}$ or $\mathrm{Xe}$ was usually used as a calibration gas. The energy resolution, as measured for the $\mathrm{Ar}^{+}{ }^{2} \mathrm{P}_{3 / 2}$ peak, was about $13 \mathrm{meV}$.

\section{Results and discussion}

\section{$3.1 \mathrm{As}_{2}$}

The $A s_{2}$ spectrum is shown in Fig. 1. The valence electronic configuration of $\mathrm{As}_{2}$ can be described as $1 \sigma_{\mathrm{g}}{ }^{2} l \sigma_{\mathrm{u}}{ }^{2} 2 \sigma_{\mathrm{g}}{ }^{2} 1 \pi_{\mathrm{u}}{ }^{4}$. Ionization of the $1 \pi_{\mathrm{u}}$ orbital results in the ${ }^{2} \Pi_{\mathrm{u}}$ band in $\mathrm{As}_{2}{ }^{+}$, which is split by the spin-orbit effect. The removal of a $2 \sigma_{\mathrm{g}}$ electron gives rise to the sharp ${ }^{2} \Sigma_{\mathrm{g}}{ }^{+}$band with little vibrational excitation. Extensive vibrational structure was observed for the ${ }^{2} \Pi_{u 3 / 2}$ and ${ }^{2} \Pi_{u 1 / 2}$ bands, which are partially overlapped. This makes it difficult to assign exactly where the ${ }^{2} \Pi_{u 1 / 2}$ band starts. From the assignments given in Fig. 1, vibrational frequencies of $360 \mathrm{~cm}^{-1}$ and $450 \mathrm{~cm}^{-1}$ were derived for the ${ }^{2} \Pi_{u 1 / 2}$ and ${ }^{2} \Pi_{u 3 / 2}$ states, respectively. In light of the bonding character of the $1 \pi_{\mathrm{u}}$ orbital, a vibrational frequency of $450 \mathrm{~cm}^{-1}$ for the ${ }^{2} \Pi_{\mathrm{u} 3 / 2}$ state is surprising, because it is even larger than that of the neutral ground state $\left(429 \mathrm{~cm}^{-1}[18]\right.$ ) Furthermore, the large difference between the vibrational frequencies of the two spinorbit states is also unexpected. A similar situation has been encountered in the ${ }^{2} \Pi_{u l / 2}$ and ${ }^{2} \prod_{u 3 / 2}$ states of $\mathrm{Br}_{2}{ }^{+}$, which was found to be caused by an avoided curve crossing 
of the ${ }^{2} \Pi_{\mathrm{u} 1 / 2}$ state from a relativistic $\mathrm{CI}$ calculation [19]. Such a calculation is unde; way for $\mathrm{As}_{2}{ }^{+}$to explain our observation [20]. The experimentally-derived spectroscopic constants for $\mathrm{As}_{2}{ }^{+}$are listed in Table II.

\section{$3.2 \mathrm{P}_{4}$ and $\mathrm{As}_{4}$}

The vibrationally-resolved spectra of $\mathrm{P}_{4}$ and $\mathrm{As}_{4}$ are shown in Figs. 2 and 3, respectively. These two molecules are isoelectronic and have the same tetrahedral geometry. Thus, the two spectra are very similar, with the $\mathrm{P}_{4}$ spectra being better resolved. The valence electronic configuration of $\mathrm{P}_{4}$ and $\mathrm{As}_{4}$ can be written as $\left(1 a_{1}\right)^{2}\left(1 t_{2}\right)^{6}\left(2 a_{1}\right)^{2}\left(2 t_{2}\right)^{6}(1 e)^{4}$, where the $1 a_{1}$ and $1 t_{2}$ orbitals are mainly of the valence $s$ character and the $2 a_{1}, 2 t_{2}$, and 1 e orbitals are primarily composed of the valence $p$ character. As shown in Figs. 2 and 3, only the ionizations of the outermost three orbitals were observed.

Before analyzing the spectra, it is instructive to consider the normal vibrational modes and frequencies of the neutral molecules. For a tetrahedral $\mathbf{M}_{4}$ molecule, there are three normal modes of vibration, which are listed in Table III for $\mathrm{P}_{4}$ and $\mathrm{As}_{4}$ [21].

The $\left(2 a_{1}\right)^{-1}$ band in each spectrum consists of a well-resolved vibrational progression. Both from symmetry consideration and from the observed spacings, this progression should be the $v_{1}$ vibrational progression. The frequencies are $560 \mathrm{~cm}^{-1}$ and $350 \mathrm{~cm}^{-1}$ for $\mathrm{P}_{4}{ }^{+}$and $\mathrm{As}_{4}{ }^{+}$, respectively. The $\left(2 \mathrm{t}_{2}\right)^{-1}$ and $(1 \mathrm{e})^{-1}$ bands are much more complicated because of the Jahn-Teller effect, which is discussed in the next section.

\subsection{The Jahn-Teller effect}

The Jahn-Teller theorem states that highly symmetrical molecular configurations in degenerate electronic states are unstable with respect to certain asymmetric vibrations [22], which carry the nuclei over into distorted configurations and lift the electronic degeneracies. The Jahn-Teller effect is often important for small clusters, because 
electronic degeneracy is very common in these systems [23,24]. It dictates the geometrical and electronic structures of these species.

In discussing the Jahn-Teller problem, it is essential to know which asymmetrical vibrational modes are active in the vibronic coupling when more than one Jahn-Teller active vibrational mode is present. Ionization of an electron from a le orbital would produce $a^{2} E$ state, for which only the $v_{2}(e)$ mode is active [25]. Removal of an electron from a $2 t_{2}$ orbital would give rise to a ${ }^{2} T_{2}$ state, for which both the $v_{2}(e)$ and the $v_{3}\left(t_{2}\right)$ modes can be involved [25]. Furthermore, spin-orbit splitting is also possible in the ${ }^{2} T_{2}$ state.

Expanded spectra of the (1e) $)^{-1}$ and $\left(2 \mathrm{t}_{2}\right)^{-1}$ bands are shown in Figs. 4 and 5 for $\mathrm{P}_{4}{ }^{+}$and $\mathrm{As}_{4}{ }^{+}$, respectively. Vibrational structure was partially resolved in these two bands for $\mathrm{P}_{4}{ }^{+}$, but not as well for the $\mathrm{As}_{4}{ }^{+}$spectrum due to its smaller vibrational frequencies. Fortunately, the understanding of the $\mathrm{P}_{4}{ }^{+}$spectrum should be sufficient for this series of tetramers. It can be seen from Fig. 4 that the $(1 \mathrm{e})^{-1}$ band of $\mathrm{P}_{4}{ }^{+}$is split into two bands, one peaking at $-9.4 \mathrm{eV}$ and the other at $\sim 9.9 \mathrm{eV}$. The observed vibrational frequencies are $310 \mathrm{~cm}^{-1}$ for the first band and $270 \mathrm{~cm}^{-1}$ for the second. These values are close is the ground state $v_{2}$ vibrational frequency (Table III). The (le) $)^{-1}$ band of $\mathrm{As}_{4}{ }^{+}$closely resembles that of $\mathrm{P}_{4}{ }^{+}$. The Jahn-Teller splitting energies are almost identical $(\sim 0.5 \mathrm{eV})$.

The $\left(2 \mathrm{t}_{2}\right)^{-1}$ band of $\mathrm{As}_{4}{ }^{+}$was assigned previously to only two spin-orbit split components [14]. As can be seen from Figs. 4 and 5, this band is composed of three components, indicating that the Jahn-Teller effect is also important. Comparing the $\left(2 t_{2}\right)^{-1}$ bands of $\mathrm{P}_{4}^{+}, \mathrm{As}_{4}{ }^{+}$, and $\mathrm{Sb}_{4}{ }^{+}[26]$ indicates that the separation between the lowest energy component and the two components at higher energies increases from $\mathrm{P}_{4}{ }^{+}$ to $\mathrm{Sb}_{4}{ }^{+}$, suggesting that the lowest energy component is due to the spin-orbit splitting. Well-resolved vibrational structure was observed for this component in $\mathrm{P}_{4}{ }^{+}$. The vibrational frequency is $400 \mathrm{~cm}^{-1}$, consistent with the $v_{3}$ vibrational mode. The two 
components at higher energy should he due to the Jahn-Teller effect. No simple vibrational progression was observed for any of these components in $\mathrm{P}_{4}{ }^{+}$, meaning that both the $v_{2}$ and the $v_{3}$ modes are active in the vibronic interaction.

$\mathrm{P}_{4}$ and As4 are simple examples of tetrahedral clusters. The elucidation of the Jahn-Teller effect in these simple systems may help us understand more complicated $\mathrm{M}_{4}$ clusters.

\section{Conclusion}

In summary, we have obtained high resolution photoelectron spectra for three Group $\mathrm{V}$ element clusters, $\mathrm{As}_{2}, \mathrm{As}_{4}$, and $\mathrm{P}_{4}$. Vibrational structure was resolved for the three molecules and vibrational frequencies were derived for the final ionic states. It was found that the vibrational frequencies of the ${ }^{2} \Pi_{\mathrm{u} 1 / 2}$ and ${ }^{2} \Pi_{\mathrm{u} 3 / 2}$ states of $\mathrm{As}_{2}{ }^{+}$are surprisingly different. Very well resolved vibrational spectra were obtained for the $\left(2 \mathrm{a}_{1}\right)^{-1}$ bands of $\mathrm{P}_{4}$ and $\mathrm{As}_{4}$. The Jahn-Teller effect was found to be important in both the $(1 e)^{-1}$ and $\left(2 t_{2}\right)^{-1}$ bands of these clusters. Both the $v_{2}$ and $v_{3}$ normal modes are active in the vibronic interaction of the $\left(2 \mathrm{t}_{2}\right)^{-1}$ band.

\section{Acknowledgement}

This work was supported by the Director, Office of Energy Research, Office of Basic Energy Sciences, Chemical Sciences Division of the U.S. Department of Energy under the Contract No. DE-AC03-76SF00098. 


\section{References}

1. See for example, a. Kappes, M.M., Chem. Rev. 요, 369 (1988); b. Chem. Rev. 86, 491-635 (1986), special issue on 'gas-phase clusters'; c. Martin, T.P., Phys. Rep. 25, 167 (1983).

2. Ervin, K.M., Ho, J., and Lineberger, W.C., J. Chem. Phys. 89,4514 (1988).

3. Cheshnovsky, O., Yang, S.H., Pettiette, C.C., Craycraft, M.J., and Smalley, R.E., Rev. Sci. Instrum. 58, 2131 (1987).

4. Ebehardt, W., Fayet, P., Cox, D., Fu, Z., Kaldor, A., and Sondericker, D., Phsica Scripta, the current issue, (19xx).

5. Wang, L.S., Reutt-Robey, J.E., Niu, B., Lee, Y.T., and Shirley, D.A., in Proceedings of the Fourth International Conference on Electron Spectroscopy, July 10-14, 1989, Honolulu, U.S.A., J. Electron Spectrosc. Relat. Phenom., in press.

6. Nesmeyanov, A.N., Gary, R. (Ed.), Vapor Pressure of the Chemical Elements, p. 286-306, Elsevier, Amsterdam, 1959.

7. Bulgin, D.K., Dyke, J.M., and Morris, A., J. Chem. Soc. Faraday Trans. 2 72, 2225 (1976).

8. Dyke, J.M., Elbel, S., Morris, A., and Stevens, J.C.H., J. Chem. Soc. Faraday Trans. 2 82, 637 (1986).

9. Potts, A.W., Glen, K.G., and Price, W.C., Faraday Discuss. Chem. Soc. 54, 65 (1972).

10. Bock, H. and Muller, H., Inorg. Chem. 23, 4365 (1984).

11. Evans, S., Joachim, P.J., Orchard, A.F., and Turner, D.W., Int. J. Mass Spectrom. Ion Phys. 9, 41 (1972).

12. Brundle, C.R., Kuebler, N.A., Robin, M.B., and Basch, H., Inorg. Chem. 11, 20 (1972).

13. Elbel, S., Dieck, H.T., Walther, H., and Krizek, J., Inorg. Chim. Acta 53, L101 
(1981).

14. Dyke, J.M., Elbel, S., Morris, A., and Stevens, J.C.I., J. Chem. Soc. Faraday Trans. 2 \$2, 637 (1986).

15. Elbel, S., Kudnig, J., Grodzicki, M., and Lempka, H.J., Chem. Phys. Lett. $\underline{109}$, 312 (1984).

16. Dyke, J.M., Morris, A., and Stevens, J.C.H., Chem. Phys. 102, 29 (1986).

17. Pollard, J.E., Trevor, D.J., Lee, Y.T., and Shirley, D.A., Rev. Sci. Instrum. 52 , 1837 (1981).

18. Huber, K.P. and Herzberg, G., Spectroscopic Constants of Diatomics, Van Nostrand Reinhold, New York, 1979.

19. Balasubramanian, K., Chem. Phys. 119,41 (1988).

20. Balasubramanian, K., private communication.

21. Bondybey, V.E., Schwartz, G.P., and Griffiths, J.E., J. Mol. Spectrosc. 89 , 328 (1981).

22. Jahn, H.A. and Teller, E., Proc. Roy. Soc. A 161, 20 (1937).

23. Gerber, W.H. and Schumacher, E., J. Chem. Phys. 69, 1692 (1978).

24. Morse, M.D., Hopkins, J.B., Langridge-Smith, P.R.A., and Smalley, R.E., J. Chem. Phys. 79, 5316 (1983).

25. Herzberg, G., Molecular Spectra and Molecular Structure: III. Electronic Spectra and Electronic Structure of Polyatomic Molecules, p. 50, Van Nostrand Reinhold, New York, 1966.

26. Wang, L.S., Lee, Y.T., and Shirley, D.A., to be published. 
Table I. Experimental conditions

\begin{tabular}{lllll}
\hline & $\mathrm{T}(\mathrm{K})^{\mathrm{a}}$ & $\mathrm{P}(\mathrm{torr})^{\mathrm{b}}$ & $\phi(\mathrm{mm})^{\mathrm{c}}$ & Starting materials \\
\hline $\mathrm{As}_{2}$ & $\sim 1400$ & $350(\mathrm{Ne})$ & 0.13 & Cu3As \\
$\mathrm{As}_{4}$ & -650 & $200(\mathrm{He})$ & 0.16 & Pure arsenic \\
$\mathrm{P}_{4}$ & $\sim 620$ & $500(\mathrm{He})$ & 0.16 & Red phosphorus \\
\hline
\end{tabular}

a. Oven temperature $\pm 50 \mathrm{~K}$.

b. Carrier gas pressure.

c. Nozzle diameter. 
Table $\mathrm{L}$. Spectroscopic constants of $\mathrm{As}_{2}{ }^{+}$.

\begin{tabular}{llll}
\hline & ${ }^{2} \Pi_{\mathrm{u} 3 / 2}$ & ${ }^{2} \Pi_{\mathrm{u} 1 / 2}$ & ${ }^{2} \Sigma_{\mathrm{L}}{ }^{+}$ \\
\hline $\operatorname{IPad}(\mathrm{eV})^{\mathrm{a}}$ & $9.511(6)$ & $(9.903)$ & $10.228(5)$ \\
$\omega_{e}\left(\mathrm{~cm}^{-1}\right)$ & 450 & 360 & 390 \\
\hline
\end{tabular}

a. Adjabatic ionization potential. 
Table III. Normal modes of vibration of $\mathrm{P}_{4}$ and $\mathrm{As}_{4}$ from Ref. [21].

\begin{tabular}{llll}
\hline & $v_{1}\left(a_{1}\right)$ & $v_{2}(e)$ & $v_{3}\left(t_{2}\right)$ \\
\hline$P_{4}$ & $600 \mathrm{~cm}^{-1}$ & $360 \mathrm{~cm}^{-1}$ & $450 \mathrm{~cm}^{-1}$ \\
As4 & $340 \mathrm{~cm}^{-1}$ & $200 \mathrm{~cm}^{-1}$ & $250 \mathrm{~cm}^{-1}$ \\
\hline
\end{tabular}




\section{Figure captions}

Figure 1. Hel photoelectron spectrum of As2.

Figure 2. Hel photoelectron spectrum of $\mathbf{P}_{\mathbf{4}}$.

Figure 3. HeI photoelectron spectrum of $\mathrm{As}_{4}$.

Figure 4. The $(1 e)^{-1}$ and $\left(2 t_{2}\right)^{-1}$ bands of $P_{4}$. The three peaks underneath the $\left(2 t_{2}\right)^{-1}$ band indicate the three components in this band. They are three voigt functions used to fit the band.

Figure 5. The $(1 \mathrm{e})^{-1}$ and $\left(2 \mathrm{t}_{2}\right)^{-1}$ bands of As4. The three peaks underneath the $\left(2 \mathrm{t}_{2}\right)^{-1}$ band indicate the three components in this band. They are three voigt functions used to fit the band. 


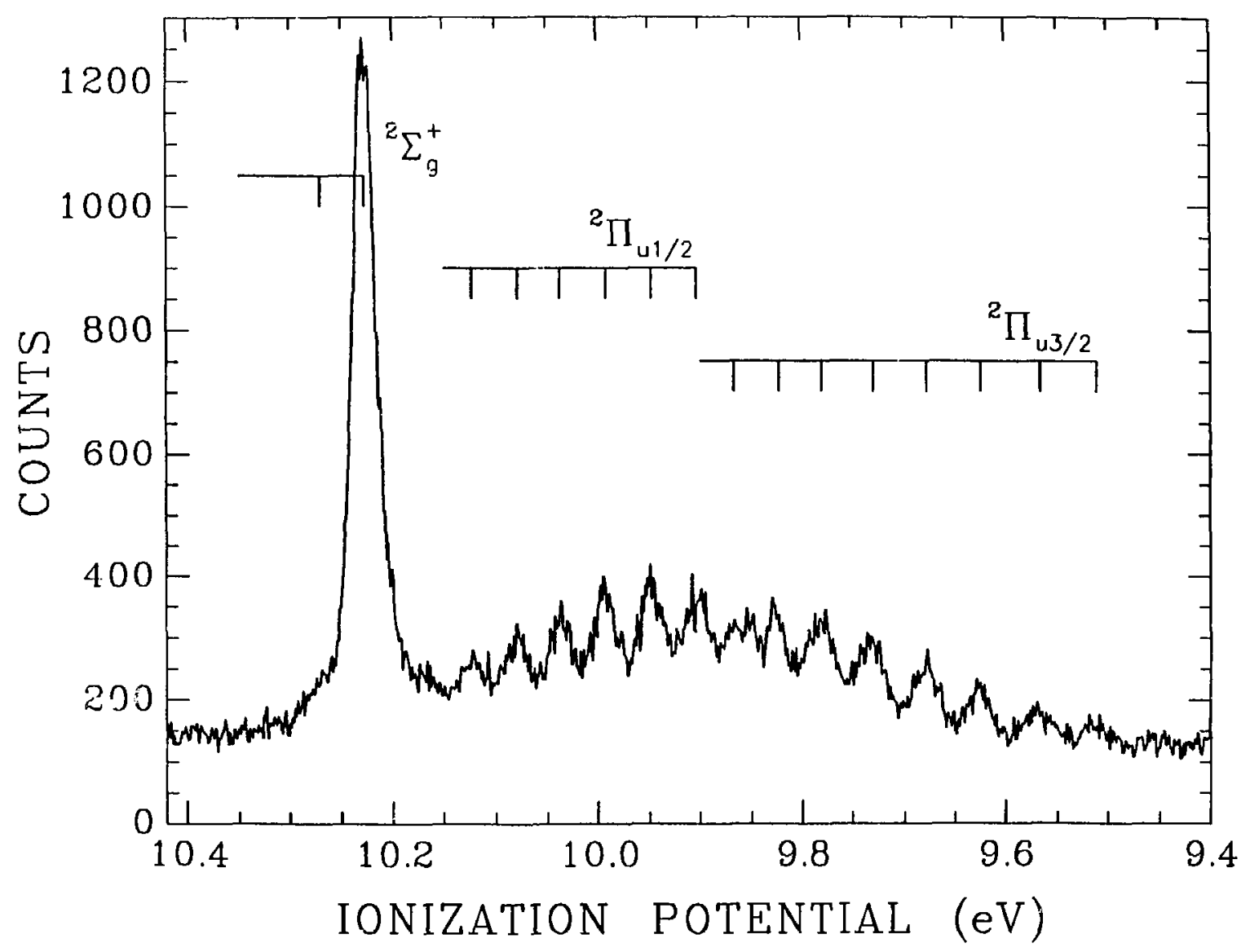




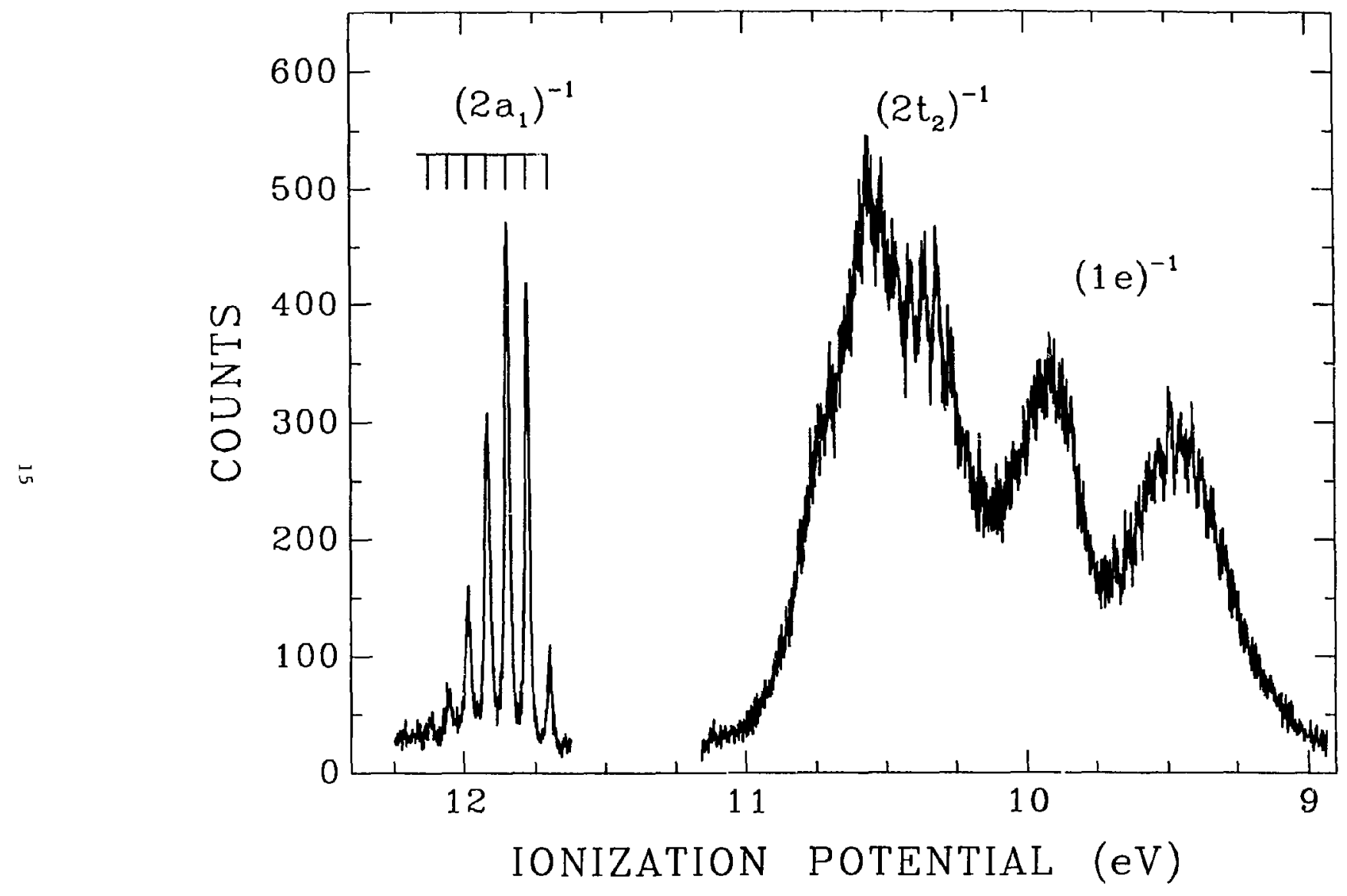




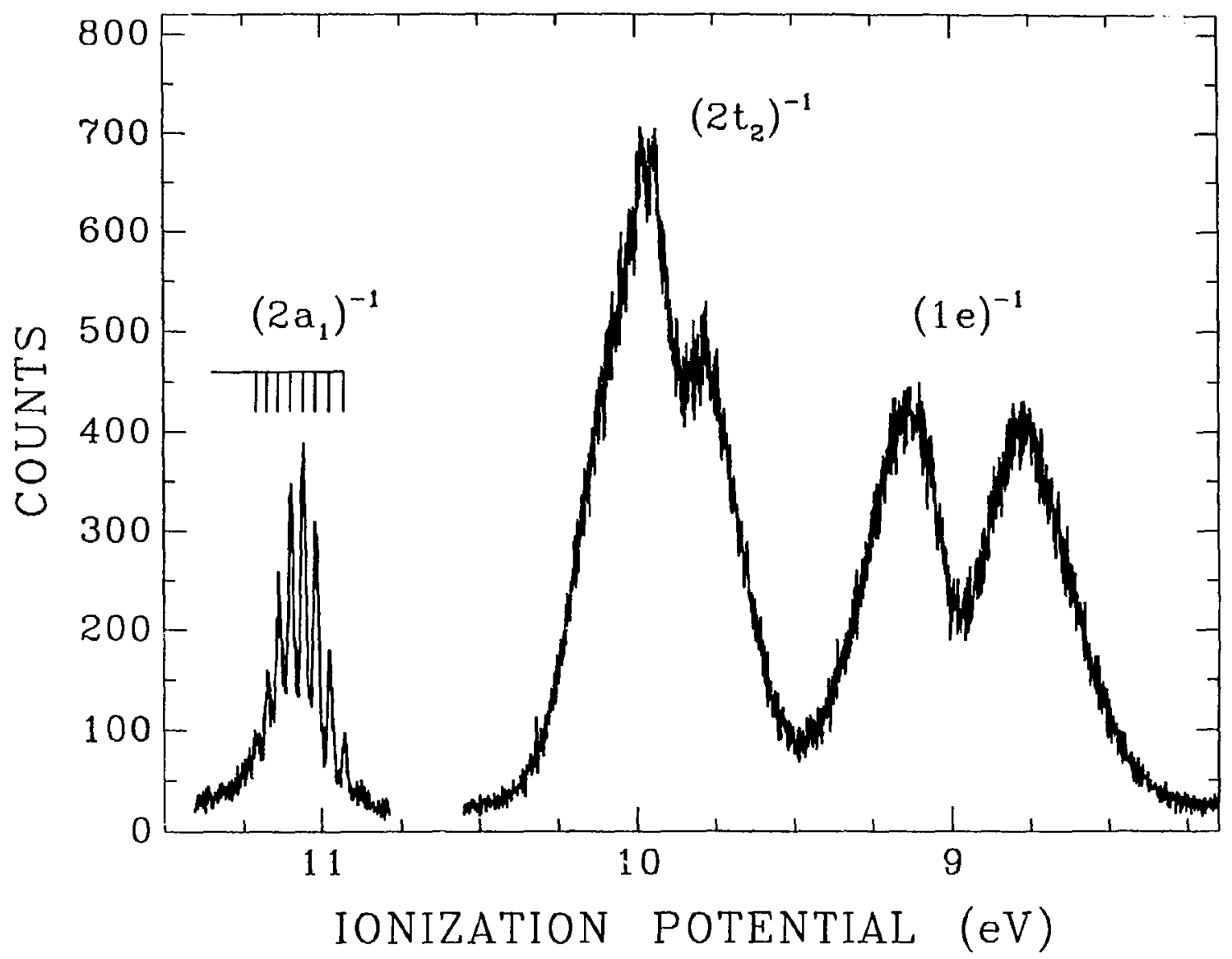




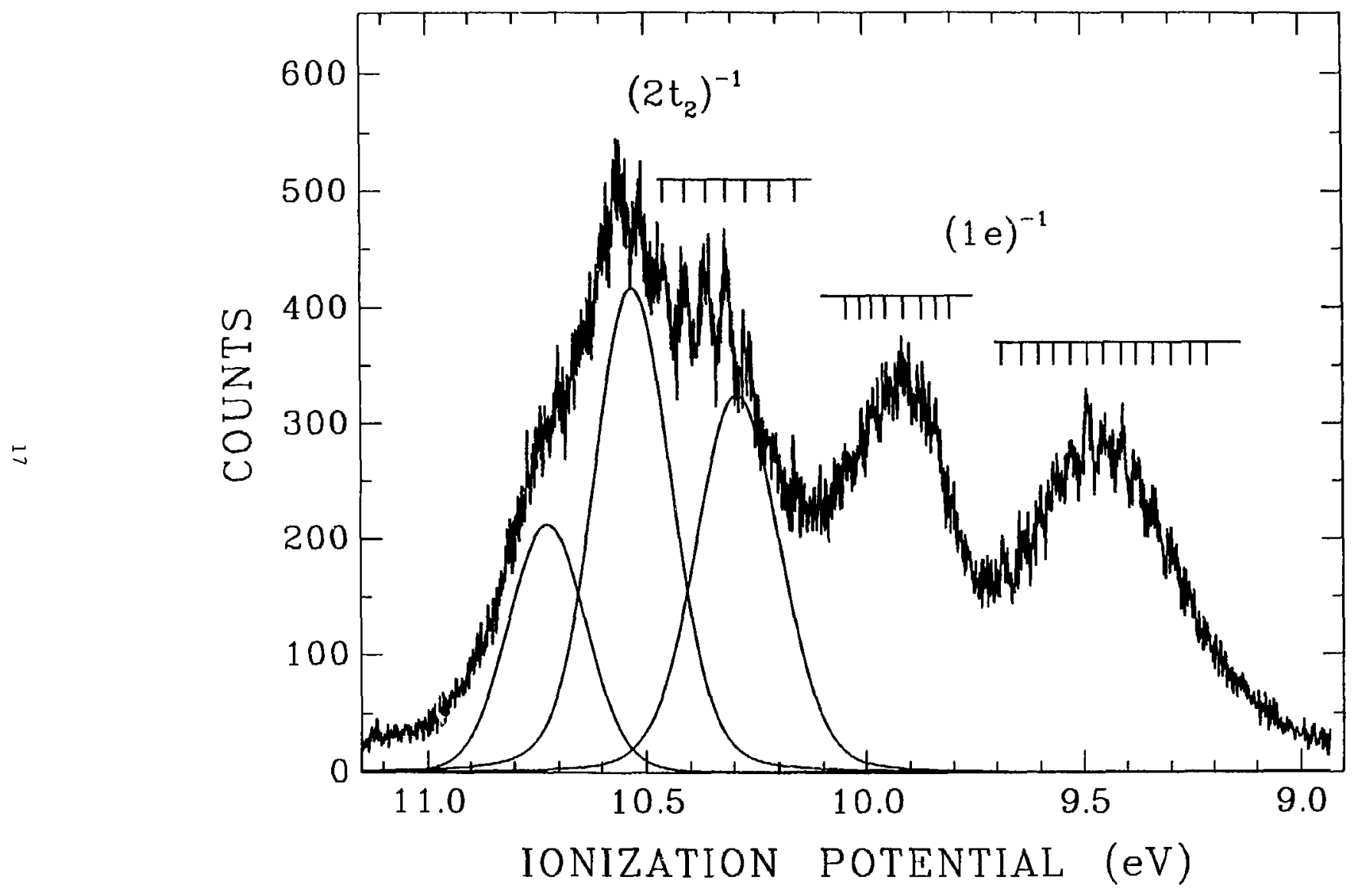




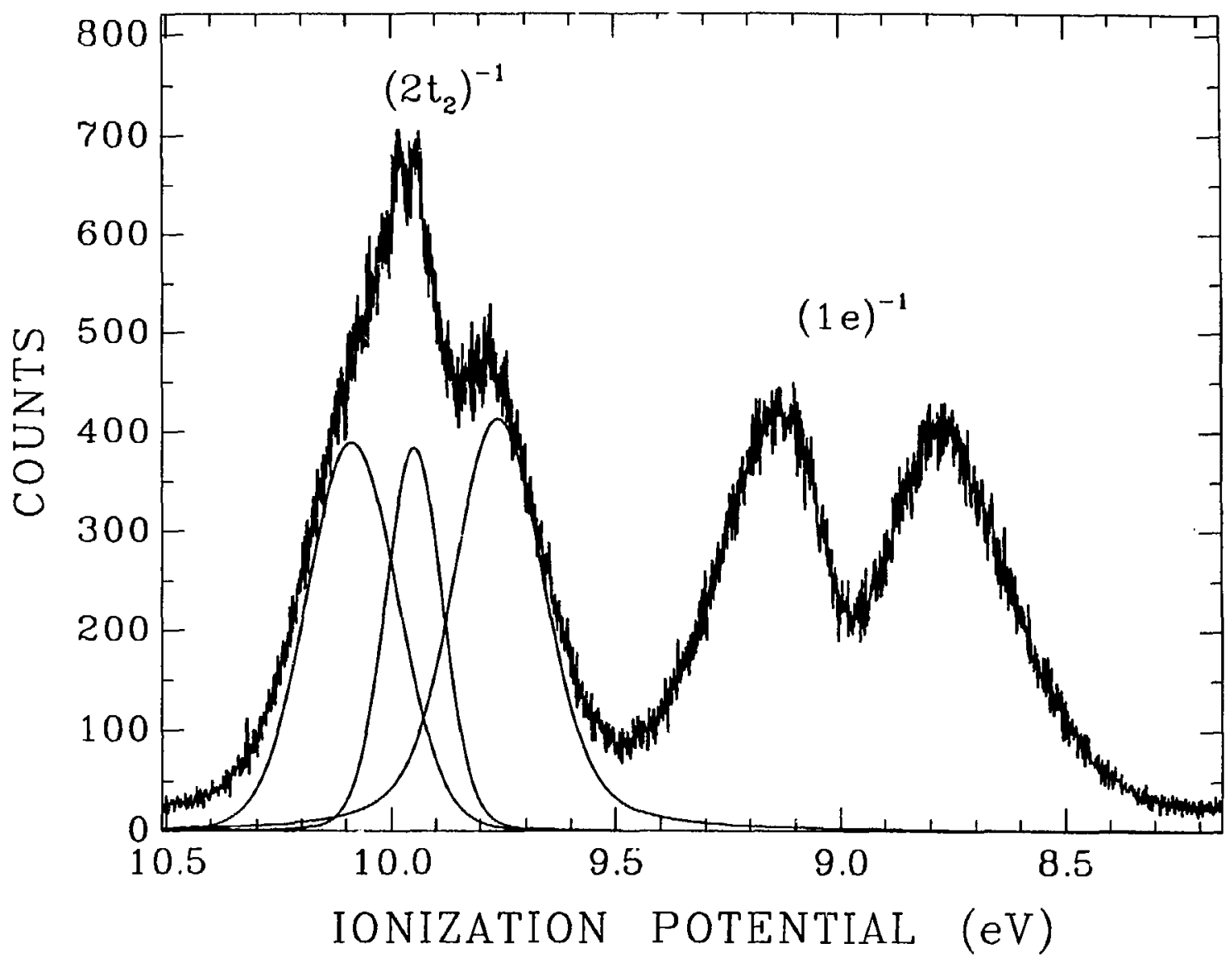

